\title{
Channelopathies and drug discovery in the postgenomic era
}

\author{
Dayue Darrel DUAN ${ }^{1, *}$, Tong-hui MA ${ }^{2, *}$ \\ ${ }^{1}$ Laboratory of Cardiovascular Phenomis, Center of Biomedical Research Excellence, Department of Pharmacology, Center for Molecu- \\ lar Medicine, University of Nevada School of Medicine, Reno, Nevada 89557, USA; ${ }^{2}$ Central Research Laboratory, Jilin University \\ Bethune Second Hospital, Changchun 130041, China
}

Acta Pharmacologica Sinica (2011) 32: 673-674; doi: 10.1038/aps.2011.73

Ion channels are a diverse group of pore-forming proteins that provide selective pathways for the movement of ions $\left(\mathrm{Na}^{+}, \mathrm{K}^{+}\right.$, $\mathrm{Ca}^{2+}, \mathrm{Cl}^{-}$, etc) across the lipid membrane barrier. Aquaporins facilitate water movement across cell membranes in response to osmotic gradients. There is an increasing body of information on the molecular structure and functional roles of ion and water channels in health and disease, linking channel function at the molecular level to organ physiology. Because ion channels play essential roles in all cells, defects in ion channels are associated with a wide variety of pathophysiological conditions and human diseases. Diseases caused by disturbed function of ion channel subunits or regulatory proteins have been defined as "channelopathies" ${ }^{[1,2]}$. In the postgenomic era the rapid progress in the molecular identification of genes for new ion channels and elucidation of their transport properties, physiological functions, and disease relevant mutations has significantly advanced the knowledge of channelopathies and potential new therapies ${ }^{[3-9]}$. For examples, the discovery of aquaporin water channels, a family of integral membrane proteins that selectively transport water, has led to the identification of water channelopathies including autosomal dominant and recessive forms of hereditary nepherogenic diabetes insipidus caused by aquaporin-2 mutations ${ }^{[10]}$, congenital cataracts incurred by aquaporin- 0 mutations ${ }^{[11]}$ and aquired neuronal inflammatory disease neuromyelitis optica in which pathogenic autoantibodies target aquaporin- $4^{[12]}$. Impaired $\mathrm{Cl}^{-}$ transport caused by mutations in genes belonging to distinct $\mathrm{Cl}^{-}$channel families has been found to cause diverse diseases such as cystic fibrosis, myotonia, epilepsy, hyperekplexia, lysosomal storage disease, deafness, renal salt loss, kidney stones,

\footnotetext{
* To whom correspondence should be addressed.

E-mail dduan@medicine.nevada.edu (Dayue Darrel DUAN); math108@gmail.com (Tong-hui MA)

Received 2011-05-14 Accepted 2011-05-16
}

osteopetrosis, and cardiovascular diseases ${ }^{[7,13,14]}$. In addition, the studies on the role of ion channel regulatory proteins, including the sub-membrane adapter ankyrins and alpha-1 syntrophin, membrane coat protein caveolin-3, signaling platform yotiao, and lamins, have also provided novel insights into understanding of human diseases ${ }^{[15]}$.

In the international symposium on "Channelopathy and Drug Discovery" held in Jilin University Bethune Second Hospital, Changchun, Jilin, China on October 14-16, 2010, about 40 accomplished scientists from the United States, United Kingdom, Canada, Germany, Italy, South Korea, and different regions of China were invited to present their latest research in the fields of channelopathies, with particular focus on aquaporins and chloride channels. In facing the challenges of developing novel pharmacological therapies targeting channelopathies, new strategies of modern drug discovery, including methodology of high throughput screening from natural products and approaches of combinatorial and medicinal chemistry were also discussed. This symposium provided an important platform for domestic and overseas scientists to communicate on the latest academic achievements in channelopathies and drug discovery.

In this Special Issue of Acta Pharmacologica Sinica we have assembled a series of review articles, original research contributions, and perspectives from the speakers of the international symposium to provide the most up-to-date information on our understanding of the mechanisms of aquaporin and $\mathrm{Cl}^{-}$channelopathies and related new strategies and targets for drug discovery. To cover the topics of channelopathies other than aquaporin and $\mathrm{Cl}^{-}$channels we extended the invitation to contribute papers from several leading scientists who did not attend the symposium. These articles in this special issue impart a summary of the recent advances in the study of molecular mechanisms and functional roles of a variety of ion channels including $\mathrm{Na}^{+[16]}, \mathrm{K}^{+[17-20]}, \mathrm{Ca}^{2+[21]}, \mathrm{Cl}^{-[22-26]}$, 
$\mathrm{TRP}^{[27,28]}$, TREK ${ }^{[29]}$ and acid-sensing $\mathrm{Ca}^{2+}$-permeable channels ${ }^{[30]}$, and aquaporins ${ }^{[31-35]}$. Advances are reported in channel integrated physiology, pharmacology and pathophysiology, and in channelopathies of the nervous ${ }^{[27-28,30,34-35]}$, cardiovascular $^{[15-18,22,25,36-37]}$, renal ${ }^{[20]}$, and reproductive ${ }^{[29,31-33]}$ systems. In addition, the role of pathological release of $\mathrm{Ca}^{2+}$ from the sarcoplasmic reticulum via cardiac ryanodine receptors (RyR2) in cardiac arrhythmias and RyR2 as a promising novel target for antiarrhythmic therapy are also discussed ${ }^{[36]}$.

We believe that publication of this special issue will also highlight the impact of Chinese scientists in this field and promote international academic exchange and collaborations to accelerate understanding of human disease mechanisms and discovery of new treatments.

\section{References}

1 Hoffman EP. Voltage-gated ion channelopathies: inherited disorders caused by abnormal sodium, chloride, and calcium regulation in skeletal muscle. Annu Rev Med 1995; 46: 431-41.

2 Wang J, Zhou J, Todorovic SM, Feero WG, Barany F, Conwit R, et al. Molecular genetic and genetic correlations in sodium channelopathies: lack of founder effect and evidence for a second gene. Am J Hum Genet 1993; 52: 1074-84.

3 Andavan GS, Lemmens-Gruber R. Voltage-gated sodium channels: mutations, channelopathies and targets. Curr Med Chem 2011; 18 : 377-97.

4 Dudley SC Jr. Ion channelopathies: a tapped-out mine? Am J Physiol Heart Circ Physiol 2011; 300: H716-H717.

5 Kass RS. The channelopathies: novel insights into molecular and genetic mechanisms of human disease. J Clin Invest 2005; 115: 1986-9.

6 Mohler PJ, Bennett V. Ankyrin-based cardiac arrhythmias: a new class of channelopathies due to loss of cellular targeting. Curr Opin Cardiol 2005; 20: 189-93.

7 Planells-Cases R, Jentsch TJ. Chloride channelopathies. Biochim Biophys Acta 2009; 1792: 173-89.

8 Tfelt-Hansen PC, Koehler PJ. One hundred years of migraine research: major clinical and scientific observations from 1910 to 2010 . Headache 2011; 51: 752-78.

9 Zhou P, Wang J. Genetic testing for channelopathies, more than ten years progress and remaining challenges. J Cardiovasc Dis Res 2010; 1: 47-9.

10 Loonen AJ, Knoers NV, van Os CH, Deen PM. Aquaporin 2 mutations in nephrogenic diabetes insipidus. Semin Nephrol 2008; 28: 25265.

11 Chepelinsky AB. Structural function of MIP/aquaporin 0 in the eye lens; genetic defects lead to congenital inherited cataracts. Handb Exp Pharmacol 2009; 265-97.

12 Jarius S, Paul F, Franciotta D, Waters P, Zipp F, Hohlfeld R, et al. Mechanisms of disease: aquaporin-4 antibodies in neuromyelitis optica. Nat Clin Pract Neurol 2008; 4: 202-14.

13 Duan D. Phenomics of cardiac chloride channels: the systematic study of chloride channel function in the heart. J Physiol 2009; 587: 2163-77.

14 Duan DY, Liu LL, Bozeat N, Huang ZM, Xiang SY, Wang GL, et al. Functional role of anion channels in cardiac diseases. Acta Pharmacol Sin 2005; 26: 265-78.

15 Boudoulas KD, Mohler PJ. Beyond membrane channelopathies: alternative mechanisms underlying complex human disease. Acta Pharmacol Sin 2011; 32: 798-804.
16 Sun Y, Zhang JN, Zhao D, Wang QS, Gu YC, Ma HP, et al. Role of the epithelial sodium channel in salt-sensitive hypertension. Acta Pharmacol Sin 2011; 32: 789-97.

17 Liu Q, Kong AL, Chen R, Qian C, Liu SW, Sun BG, et al. Propofol and arrhythmias: two sides of the coin. Acta Pharmacol Sin 2011; 32: $817-23$.

18 Zhou P, Babcock J, Liu LQ, Li M, Gao ZB. Activation of human ethera-go-go related gene (hERG) potassium channels by small molecules. Acta Pharmacol Sin 2011; 32: 781-8.

19 Quan Y, Barszczyk A, Feng ZP, Sun HS. Current understanding of $\mathrm{K}_{\text {ATP }}$ channels in neonatal diseases related to insulin secretion disorders. Acta Pharmacol Sin 2011; 32: 765-80.

20 Sun Y, Zhou H, Yang BX. Drug discovery for polycystic kidney disease. Acta Pharmacol Sin 2011; 32: 805-16.

21 Nejatbakhsh N, Feng ZP. Calcium binding protein-mediated regulation of voltage-gated calcium channels linked to human diseases. Acta Pharmacol Sin 2011; 32: 741-8.

22 Duan DD. The CIC-3 chloride channels in cardiovascular disease. Acta Pharmacol Sin 2011; 32: 675-84.

23 Yang H, Xu LN, He CY, Liu X, Fang RY, Ma TH. CFTR chloride channel as a molecular target of anthraquinone compounds in herbal laxatives. Acta Pharmacol Sin 2011; 32: 834-9.

24 Duran C, Hartzell HC. Physiological roles and diseases of tmem16/ anoctamin proteins: are they all chloride channels? Acta Pharmacol Sin 2011; 32: 685-92.

25 Xiang SY, Ye LL, Duan LM, Liu LH, Ge ZD, Auchampach JA, et al. Characterization of a critical role for CFTR chloride channels in cardioprotection against ischemia/reperfusion injury. Acta Pharmacol Sin 2011; 32: 824-33.

26 Cai ZW, Liu J, Li HY, Sheppard DN. Targeting F508del-CFTR to develop rational new therapies for cystic fibrosis. Acta Pharmacol Sin 2011; 32: 693-701.

27 Yu SQ, Wang DH. Enhanced salt sensitivity following shRNA silencing of neuronal TRPV1 in rat. Acta Pharmacol Sin 2011; 32: 845-52.

28 Bae CY, Sun HS. TRPM7 in cerebral ischemia and potential target for drug development in stroke. Acta Pharmacol Sin 2011; 32: 725-33.

29 Buxton ILO, Heyman N, Wu YY, Barnett S, Ulrich C. A role for stretchactivated potassium currents in the regulation of uterine smooth muscle contraction. Acta Pharmacol Sin 2011; 32: 758-64.

$30 \mathrm{Li} \mathrm{MH}$, Inoue K, Si HF, Xiong ZG. Calcium-permeable ion channels involved in glutamate receptor-independent ischemic brain injury. Acta Pharmacol Sin 2011; 32: 734-40.

31 Sha XY, Xiong ZF, Liu HS, Zheng Z, Ma TH. Pregnant phenotype in aquaporin 8-deficient mice. Acta Pharmacol Sin 2011; 32: 840-4.

32 Chen Q, Duan EK. Aquaporins in sperm osmoadaptation: an emerging role for volume regulation. Acta Pharmacol Sin 2011; 32: 721-4.

33 Sha XY, Xiong ZF, Liu HS, Di SD, Ma TH. Maternal-fetal fluid balance and aquaporins: from molecule to physiology. Acta Pharmacol Sin 2011; 32: 716-20.

34 Verkman AS, Ratelade J, Rossi A, Zhang H, Tradtrantip H. Aquaporin-4: orthogonal array assembly, CNS functions, and role in neuromyelitis optica. Acta Pharmacol Sin 2011; 32: 702-10.

$35 \mathrm{Ma} \mathrm{TH}$, Gao HW, Fang XD, Yang H. Expression and function of aquaporins in peripheral nervous system. Acta Pharmacol Sin 2011; 32: 711-5.

36 McCauley MD, Wehrens XHT. Targeting ryanodine receptors for antiarrhythmic therapy. Acta Pharmacol Sin 2011; 32: 749-57.

37 Yang RG, Xi N, Lai KW, Zhong BH, Fung CK, Qu CG, et al. Nanomechanical analysis of insulinoma cells by atomic force microscopy after glucose and capsaicin stimulation. Acta Pharmacol Sin 2011; 32: 853-60. 